\title{
Elastic and dynamic response characteristics of kenaf/polypropylene composites
}

\author{
N. V. David, S. Khairiyah \& P. P. Anwar Majeed \\ Faculty of Mechanical Engineering, Universiti Teknologi, Malaysia
}

\begin{abstract}
The elastic and dynamic characteristics of natural fibre based materials are of particular concern for packaging applications. In this study, the tensile and flexural behaviour of kenaf filled polypropylene (kenaf/PP) composites are experimentally studied. The mass fraction of kenaf is varied from $0 \mathrm{wt} \%$ to $60 \mathrm{wt} \%$ in $10 \%$ increments. Two rates of extensions, namely, $2 \mathrm{~mm} / \mathrm{min}$ and $10 \mathrm{~mm} / \mathrm{min}$ are used for the tensile test. The flexural test is conducted at a rate of $1 \mathrm{~mm} / \mathrm{min}$ with reference to the ASTM D790-10 standard. The results obtained indicate that the elastic modulus of the kenaf/PP composites increases while the Ultimate Tensile Stress (UTS) of the composites decreases with increasing fibre loadings. It is found that the elastic modulus of the $60 \mathrm{wt} \%$ composite increases from $1.89 \mathrm{GPa}$ to $2.64 \mathrm{GPa}$ when the extension rate is increased from $2 \mathrm{~mm} / \mathrm{min}$ to $10 \mathrm{~mm} / \mathrm{min}$. For this same increment of extension rate, it is observed that the UTS of the composites reduces when the fibre loadings are increased with the $10 \mathrm{~mm} / \mathrm{min}$ rate registering higher UTS values than that by the $2 \mathrm{~mm} / \mathrm{min}$ rate. The stiffness of the composites in tension thus increases at the expense of their strength when the extension rate is increased. A semi-empirical model employed in this study also predicts similar responses. The stiffness of the composites in bending mode is found to be little affected by the fibre content in the neat PP. The fracture toughness of the kenaf/PP composites decreases by $56 \%$ as the fibre fraction is increased from $10 \mathrm{wt} \%$ to $60 \mathrm{wt} \%$. The first three modes of vibration of the composites are simulated using ANSYS $^{\circledR}$ ver. 12.1 program. The natural frequencies corresponding to the elastic response of the composites at the two extension rates for these modes fluctuate between $208 \mathrm{~Hz}$ and $725 \mathrm{~Hz}$.
\end{abstract}

Keywords: kenaf, agro-waste, bio-composites, tensile properties, dynamic characteristics, empirical models. 


\section{Introduction}

Advancement in materials science and engineering during the past three decades were driven mainly by the need to produce lightweight materials that are comparable in performance to their contemporaries (e.g., Huntington [1], Chalmers [2], McConnell [3], Wambua et al. [4]). There is recently an increased concern for the development of not only functionally well-designed but also sustainable materials. Material sustainability is associated with the extraction of renewable resources and disposal procedures that would not injure our ecosystem (Mohanty et al. [5], Jering et al. [6]).

Natural fibres are obtained from renewable natural resources including oil palm empty fruit bunch, coconut shell, rice husk and the kenaf plant as opposed to synthetically produced petroleum-based fibres. The growing interest in using select natural fibres over synthetic fibres to reinforce polymer based composites is mainly due to the salient advantages such as low specific weight, low cost, ease of processing and good thermal and acoustical insulating properties of the former (e.g., John and Thomas [7], Ashori [8]).

In Europe, for example, the increased usage of natural fibres especially in the automotive industry is driven by their low density and environmental concerns related to the disposal of synthetic fibres. Composite materials made of natural fibres and polypropylene, polyester or polyurethane matrix are being used in producing components such as door or trunk liners, parcel shelves, seat backs and headrests (Suddell [9]).

Packaging materials for logistical use are designed to protect fragile consumer goods from damages due to shock and/or excessive vibrations during handling and transportation. At present, expanded polystyrene (EPS) is the predominant packaging and packing materials in the market (e.g., Tolinski [10]). The disposal of the entirely polymeric, non-biodegradable and photolysis-resistant EPS often causes environmental and health concerns (e.g., Ross and Evans [11], Peter and Gerd [12]). Production of petroleum-based packing foams like EPS releases ten times the volume of carbon dioxide and consumes up to eight times the energy than that needed to produce a sample of agro-based packing material [13].

Engineering materials made from low cost indigenous agricultural wastes or by-products thus has the potential to substitute fully petroleum-based materials especially for non-load bearing applications such as packaging and packing in logistics and transportation of goods. The elastic and dynamic characteristics of natural fibre based materials are essential to and of particular concern for packaging and other shock cushioning applications.

This study presents a preliminary investigation of the tensile and flexural behaviour of kenaf filled polypropylene (kenaf/PP) composites. The mass fraction of kenaf is varied from $0 \mathrm{wt} \%$ to $60 \mathrm{wt} \%$ in $10 \%$ step increments. The tensile strength and modulus of the samples were experimentally measured at two rates of extensions, namely, $2 \mathrm{~mm} / \mathrm{min}$ and $10 \mathrm{~mm} / \mathrm{min}$. The flexural test is conducted at a rate of $1 \mathrm{~mm} / \mathrm{min}$. The variations of tensile and flexural strength as a function of fibre content are empirically modelled. The first three modes of vibration of the composites are simulated using ANSYS $^{\circledR}$ ver. 12.1 program. 


\section{Experimental}

Plain polypropylene (100\% PP) and kenaf/PP composite samples were fabricated using the standard hot press method. The temperature of the upper and lower plates in the hot press machine is set to $200^{\circ} \mathrm{C}$ and a pressure of $10 \mathrm{MPa}$ is applied to the manually mixed kenaf/PP inside a mould for 20 minutes. The mass fractions ( $\mathrm{wt} \%$ ) of kenaf used in the kenaf/PP composites are $10 \%, 20 \%, 30 \%$, $40 \%, 50 \%$ and $60 \%$. The elastic modulus and strength of the $100 \%$ PP and kenaf/PP composites are determined in tensile and flexural modes based on the BS EN ISO 527-5: 2009 and ASTM D790-10 test standards, respectively. INSTRON3382 Universal Testing Machine is used to conduct both the tensile test and the flexural test. The rate dependency of the tensile and flexural properties is measured. Two constant rates of extension (crosshead speed), namely, $2 \mathrm{~mm} / \mathrm{min}$ and $10 \mathrm{~mm} / \mathrm{min}$ are used for the tensile test. The flexural test is conducted at a crosshead speed of $1 \mathrm{~mm} / \mathrm{min}$. Five samples were used for each round of test and the average values of the properties measured are reported below.

\section{Results and discussion}

\subsection{Tensile properties}

Fig. 1 shows that the tensile modulus of the kenaf/PP composites measured at the extension rate of $10 \mathrm{~mm} / \mathrm{min}$ is greater than that recorded at the $2 \mathrm{~mm} / \mathrm{min}$ rate. The modulus of the kenaf/PP composites at both the extension rates are generally

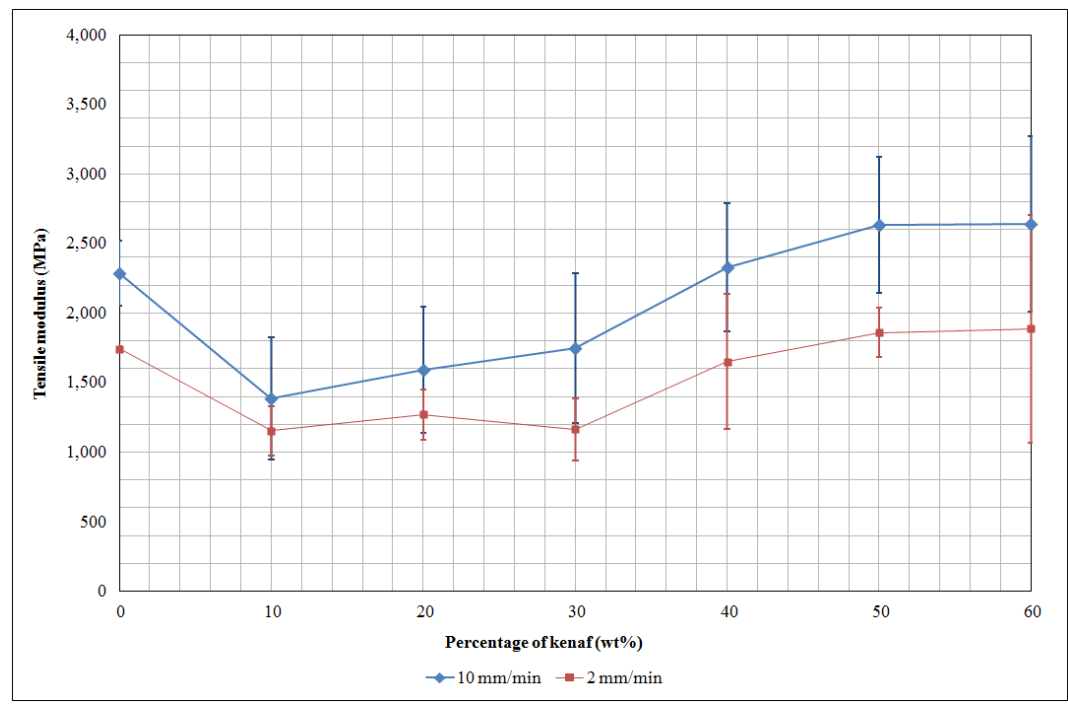

Figure 1: Comparison of elastic modulus (in tension) of the kenaf/PP composites for different extension rates. 
lower than the stiffness of the plain PP with the 10\% increment of fibre content up to $30 \mathrm{wt} \%$ loading. Increasing the amount of kenaf fibre content in the PP matrix beyond $40 \mathrm{wt} \%$ would increase the elastic modulus of the kenaf/PP composite as seen in Fig. 1. The stiffness of the plain PP is thus enhanced with a fibre addition greater than $40 \mathrm{wt} \%$. The highest values of elastic modulus of $1887 \mathrm{MPa}$ and $2640 \mathrm{MPa}$ were recorded at the $2 \mathrm{~mm} / \mathrm{min}$ and $10 \mathrm{~mm} / \mathrm{min}$ extension rates, respectively, for a $60 \mathrm{wt} \%$ fibre content.

The distribution of the fibre lengths present in the composite may influence the shape of the curve, since the load taken up by the fibres decreases as the strain increases. Addition of fibres restricts the mobility of the polymer molecules to flow freely past one another and hence cause premature failure (Hull and Clyne [14]). The formation of fibre aggregates by hydrogen bonds at the surface form a bigger structure called agglomerates. This causes the mobility of macromolecule chain be affected, where the reduction in elongation at break happens which increases the tensile modulus (David et al. [15]).

Fig. 2 shows the values of ultimate tensile stress (UTS) of the kenaf/PP composites at the extension rates of $2 \mathrm{~mm} / \mathrm{min}$ and $10 \mathrm{~mm} / \mathrm{min}$. Higher values of UTS were observed for the extension rate of $10 \mathrm{~mm} / \mathrm{min}$. The trends of both UTS curves are the same where the UTS values continually decrease with increasing percentage of kenaf. At the strain rate of $2 \mathrm{~mm} / \mathrm{min}$, the highest UTS value of $14.9 \mathrm{MPa}$ was recorded for the $100 \%$ PP sample while the lowest value of $4.17 \mathrm{MPa}$ is registered for the composite with $60 \mathrm{wt} \%$ of kenaf. Similarly, the greatest UTS value recorded at the $10 \mathrm{~mm} / \mathrm{min}$ rate is $33.7 \mathrm{MPa}$ for the plain PP and the lowest value of $6.37 \mathrm{MPa}$ was measured for the $60 \mathrm{wt} \%$ sample.

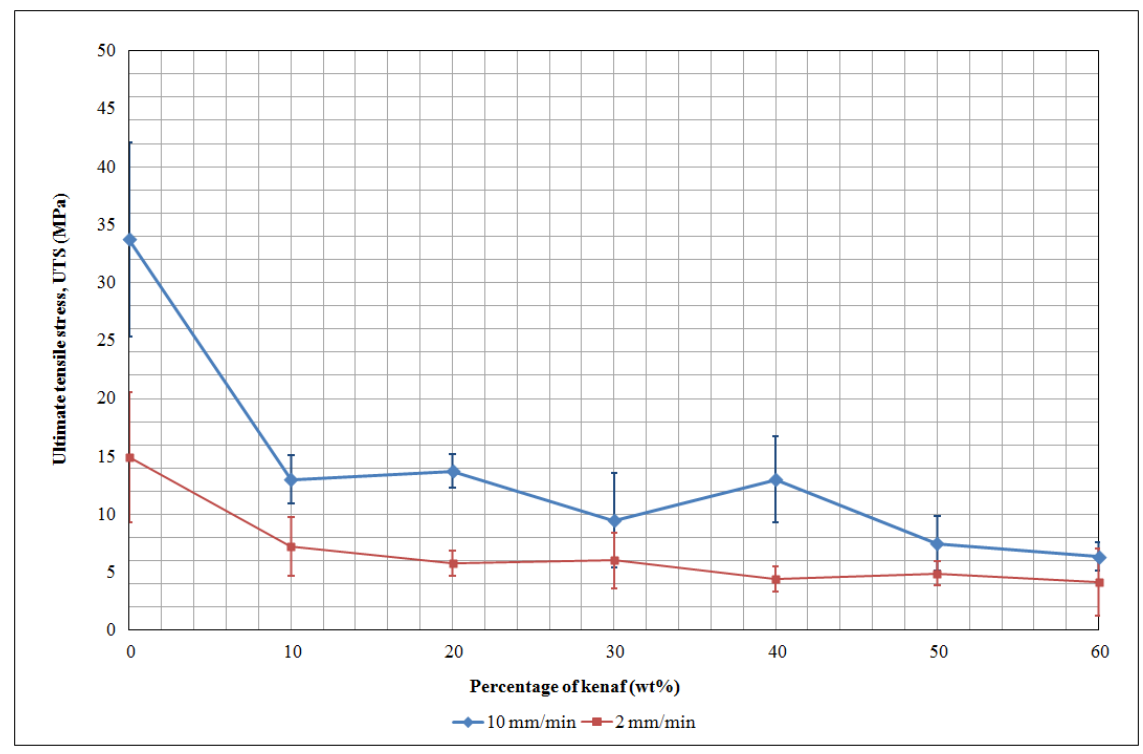

Figure 2: Comparison of ultimate tensile stress (in tension) of the kenaf/PP composites at different extension rates. 
The different surface properties of the fibre (hydrophilic) and the matrix (hydrophobic) cause discontinuities at the fibre/matrix inter-phase bonding. The distribution of kenaf fibres in the PP matrix may not be uniform due to the natural traits of fibre and matrix where the opposing natures of the fibre and the matrix surfaces may weaken the interface adhesion. Stress concentration spots are created owed to poor stress transfer from fibre to matrix. Restricted polymer chain mobility by the dispersion (i.e., fibres) and poor fibre/matrix adhesion cause stress concentration spots in the composite (David et al. [15]). Chemical treatment of the fibre surface had achieved various levels of success in improving fibre-matrix adhesion in natural fibre-reinforced composites ( $\mathrm{Li}$ et al. [16]). Chemical treatment such as maleated coupling agents may improve the adhesion between the fibre surface and the polymer matrix. The treatment modified the fibre surface and also increased the fibre strength.

The increase in tensile modulus and the decrease in UTS of the kenaf/PP composites when the extension rate is upped from $2 \mathrm{~mm} / \mathrm{min}$ to $10 \mathrm{~mm} / \mathrm{min}$ is consistent with general change in the tensile behaviour of polymeric materials from ductile to brittle as the strain rate is increased (Bower [17]).

\subsection{Modelling of ultimate tensile stress}

Fu et al. [18] studied on the effects of particle size, particle/matrix interface adhesion and particle loading on mechanical properties of particulate-polymer composites. An expression to predict the UTS of a particulate-filled composite from the UTS of the composite $\left(\sigma_{\mathrm{c}}\right)$ and the matrix $\left(\sigma_{\mathrm{m}}\right)$ is given by

$$
\sigma_{\mathrm{c}}=\sigma_{\mathrm{m}}\left(1-V_{\mathrm{f}}\right)
$$

where $V_{\mathrm{f}}$ is the volume fraction of particles, i.e., fibre. Eqn. (1) indicates that the strength of a particulate-filled composite such as the kenaf/PP composite in the present study decreases linearly with the increase in particle loading. A modified form of this equation is obtained by replacing the particle volume fraction by a power law function of the volume fraction (converted from $\mathrm{wt} \%$ ) as

$$
\sigma_{\mathrm{c}}=\sigma_{\mathrm{m}}\left(1-a V_{\mathrm{f}}^{b}\right)
$$

where $a$ and $b$ are constants that are related to particle shape and arrangement in the composite (Fu et al. [18]). Eqn. (2) still predicts a decrease in strength with increase of particle loading as eqn. (1) but the former considers fibre features and dispersion via the two constants. Figs. 3 and 4 shows the experimentally measured UTS values compared to that predicted by eqn. (2).

Fig. 3 shows that both the experimental and the predicted UTS values decrease with the addition of kenaf with an average error of 3.4\%. The semiempirical model given by eqn. (2) supported the experimentally observed mechanism of deformation as discussed in Section 3.1 above. The value of $\sigma_{\mathrm{m}}$ is constant at $14.9 \mathrm{MPa}$ while the constants $a$ and $b$ are 0.55 and 0.2 , respectively. 
Fig. 4 confirms the same trend as the experimental observation with an average error of $2.7 \%$. Value of $\sigma_{\mathrm{m}}$ is constant at $33.7 \mathrm{MPa}$ while the constants $a$ and $b$ are 0.6 and 0.2 , respectively. It is apparent that constant $a$ increases from 0.55 to 0.6 when the extension rate is increased from $2 \mathrm{~mm} / \mathrm{min}$ to $10 \mathrm{~mm} / \mathrm{min}$, whereas constant $b$ remains the same for both the extension rates.

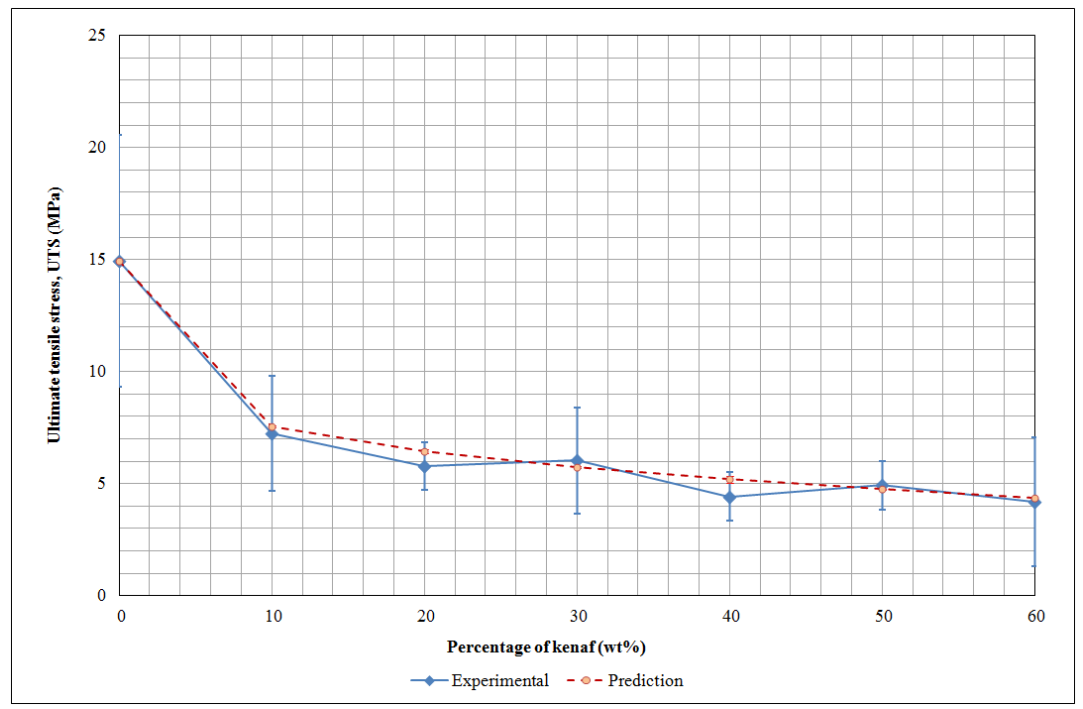

Figure 3: $\quad$ Experimental and predicted UTS at $2 \mathrm{~mm} / \mathrm{min}$ extension rate.

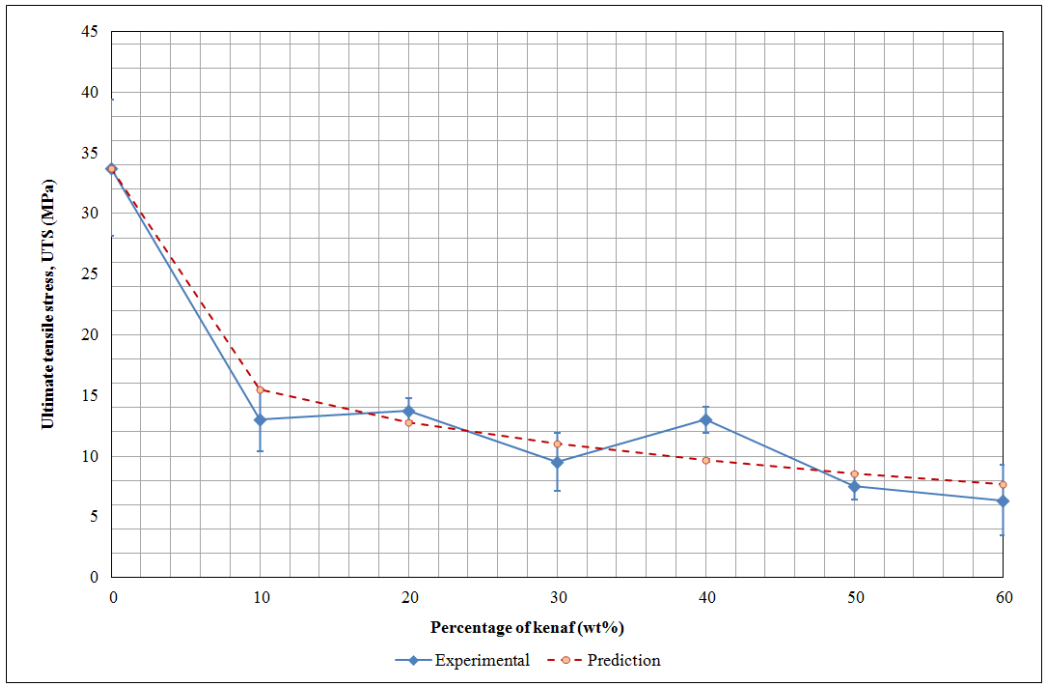

Figure 4: $\quad$ Experimental and predicted UTS at $10 \mathrm{~mm} / \mathrm{min}$ extension rate. 


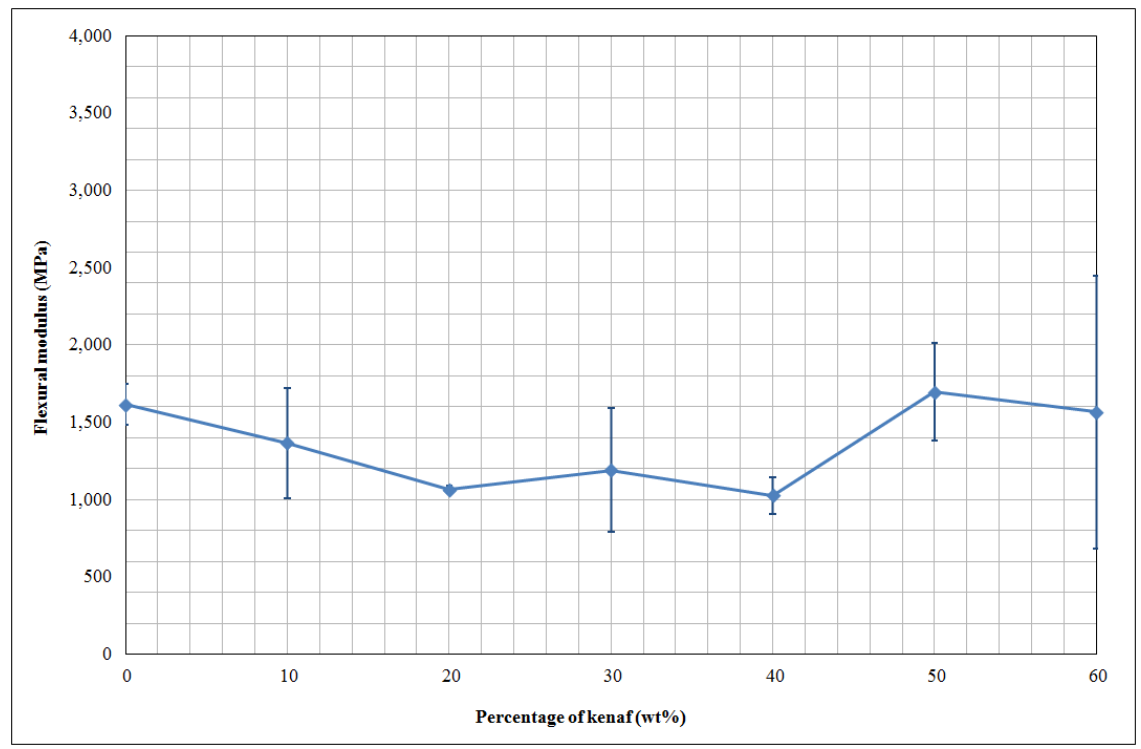

Figure 5: $\quad$ Elastic modulus (in bending mode) of the kenaf/PP composites.

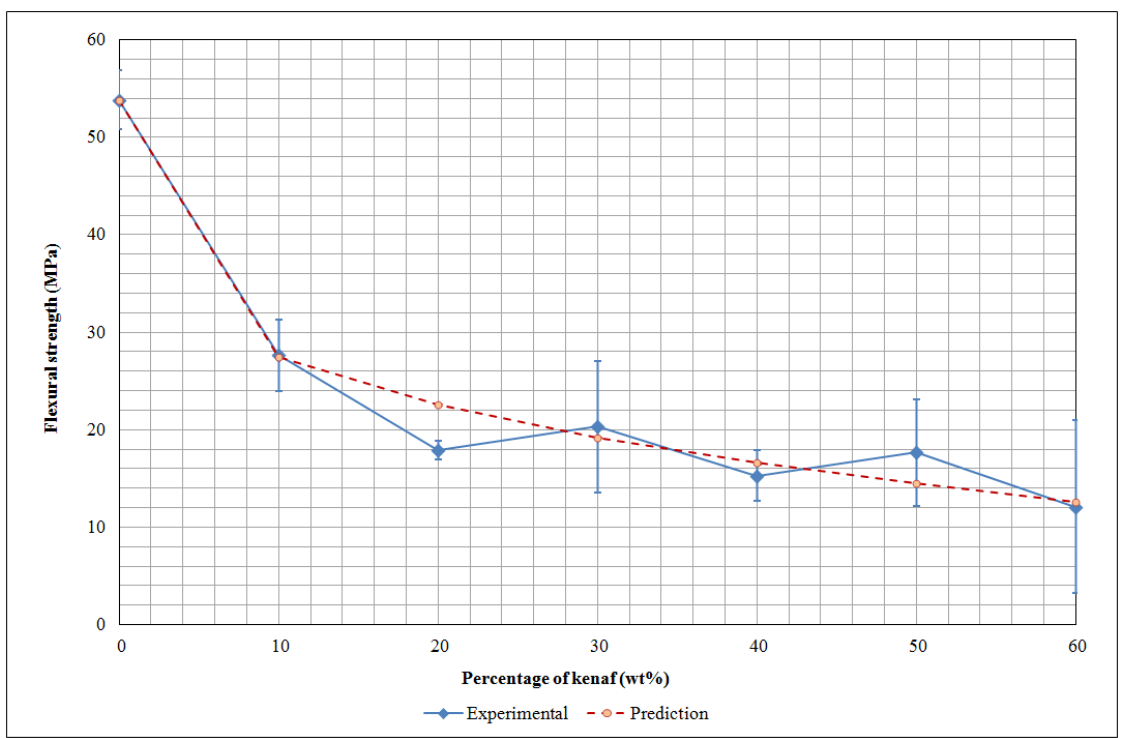

Figure 6: Experimental and predicted flexural strength of the kenaf/PP composites.

\subsection{Experimental and predicted flexural properties}

The variation of flexural modulus at the loading (bending) rate of $1 \mathrm{~mm} / \mathrm{min}$ illustrated in fig. 5 is found to be similar to tensile test elastic modulus graph (see 
fig. 1). The highest and lowest average values of flexural modulus of $1696 \mathrm{MPa}$ and $1027 \mathrm{MPa}$ were recorded for $50 \mathrm{wt} \%$ and $40 \mathrm{wt} \%$ fibre content, respectively.

The predicted flexural strengths of the composites shown in fig. 6 conform to the trend obtained experimentally with an average error of $1 \%$. The flexural strength decreases with the fibre content. The semi-empirical model given by eqn. (2) supports the experimentally observed deformation mechanism as depicted in fig. 6. It could be observed that the value of $\sigma_{\mathrm{m}}$ is constant at $53.8 \mathrm{MPa}$ while the constants $a$ and $b$ are 0.45 and 0.25 , respectively.

\section{Simulation of dynamic response}

\subsection{Simulation parameters}

The first three modes of free vibration of two composites, namely, the $50 \mathrm{wt} \%$ and $60 \mathrm{wt} \%$ samples, and the plain PP are simulated using ANSYS ${ }^{\circledR}$ ver. 12.1 software. These composites exhibited improved stiffness over the $100 \%$ PP sample and at the higher extension rate of $10 \mathrm{~mm} / \mathrm{min}$, as experimentally observed above. The experimental tensile modulus values of the composites and the plain PP for the two extension rates (see fig. 1) are used as Young's modulus of the test specimens for simulation purpose. The Poisson's ratio of the test specimens is taken as 0.3 . The volume and mass of the composites and the plain PP are measured to determine their densities. The test specimens in this modal analysis are modelled as isotropic membranes of $4 \mathrm{~mm}$ thickness. Uniform Quad Method is applied for the meshing of the models with an element size of 0.05 .

\subsection{Results}

The results of the modal analysis are tabulated in table 1 . The natural frequencies corresponding to the elastic response of the composites at the two extension rates for first three modes of vibration of the selected samples fluctuate between $208 \mathrm{~Hz}$ and $725 \mathrm{~Hz}$.

Table 1: $\quad$ Natural frequencies (in $\mathrm{Hz}$ ) of the first three modes of selected samples.

\begin{tabular}{|c|c|c|c|c|c|c|}
\hline \multirow{2}{*}{ Mode } & \multicolumn{2}{|c|}{$2 \mathrm{~mm} / \mathrm{min}$ (lower stiffness) } & \multicolumn{3}{c|}{$\begin{array}{c}10 \mathrm{~mm} / \mathrm{min} \text { (higher } \\
\text { stiffness) }\end{array}$} \\
\cline { 2 - 7 } & $100 \% \mathrm{PP}$ & $\begin{array}{c}50 \\
\mathrm{wt} \%\end{array}$ & $60 \mathrm{wt} \%$ & $\begin{array}{c}100 \% \\
\mathrm{PP}\end{array}$ & $50 \mathrm{wt} \%$ & $60 \mathrm{wt} \%$ \\
\hline $1^{\text {st }}$ & 254.2 & 208.1 & 213.06 & 291.16 & 247.59 & 252.06 \\
\hline $2^{\text {nd }}$ & 320.03 & 261.99 & 268.24 & 366.56 & 311.71 & 317.34 \\
\hline $3^{\text {rd }}$ & 633.7 & 518.78 & 531.15 & 725.84 & 617.24 & 628.38 \\
\hline
\end{tabular}

It is observed that the natural frequency increases at the higher extension rate of $10 \mathrm{~mm} / \mathrm{min}$ for which the tensile modulus is greater. This is consistent with general linear relationship between natural frequency and material stiffness. The 
deflection shapes of the first mode of the $50 \mathrm{wt} \%$ composite sample at the two extension rates are shown in fig. 7. These mode shapes correspond to $208.1 \mathrm{~Hz}$ and $247.59 \mathrm{~Hz}$ for the $2 \mathrm{~mm} / \mathrm{min}$ and $10 \mathrm{~mm} / \mathrm{min}$ extension rates, respectively.

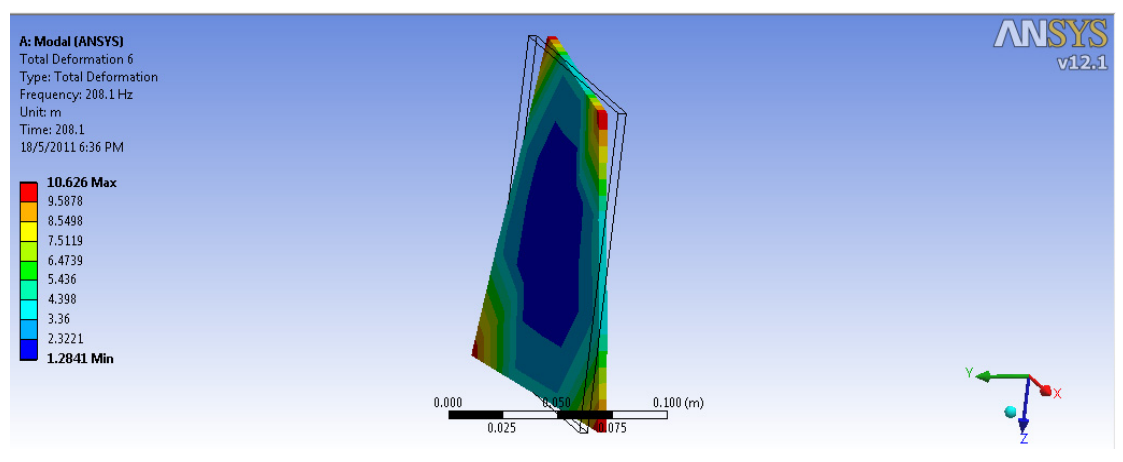

(a)

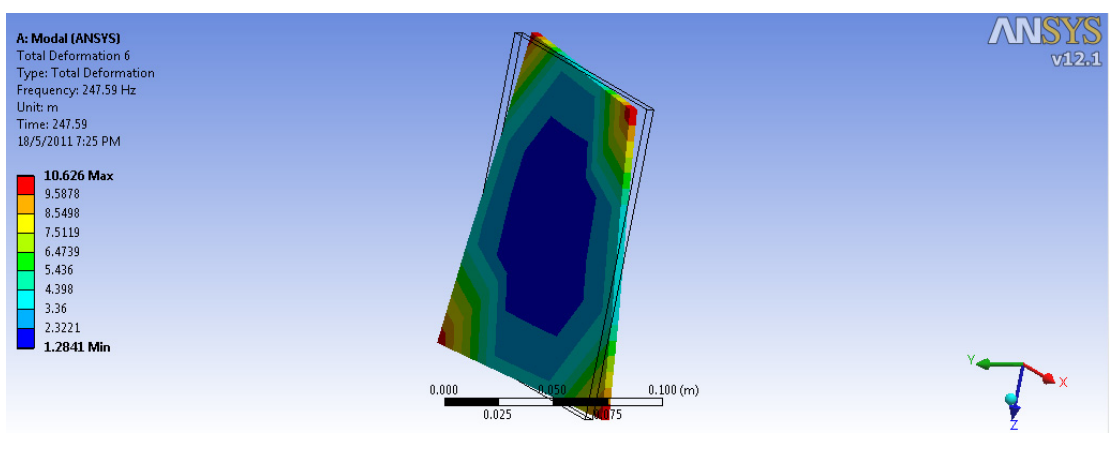

(b)

Figure 7: The deflection shapes of the first mode of the $50 \mathrm{wt} \%$ composite sample at (a) $2 \mathrm{~mm} / \mathrm{min}$, and (b) $10 \mathrm{~mm} / \mathrm{min}$ extension rates.

\section{Digest}

The tensile and flexural properties of kenaf filled polypropylene (kenaf/PP) composites with $0 \mathrm{wt} \%$ to $60 \mathrm{wt} \%$ kenaf content are experimentally determined. It is found that elastic modulus of the kenaf/PP composites increased while the tensile strength (UTS) of the composites decreased with increasing fibre content. The elastic modulus of the composites generally increased when the extension rate is increased from $2 \mathrm{~mm} / \mathrm{min}$ to $10 \mathrm{~mm} / \mathrm{min}$ with the $60 \mathrm{wt} \%$ composite registering $40 \%$ increment. For the same increment of extension rate, it is observed that the UTS of the composites reduces when the fibre loadings are increased with the $10 \mathrm{~mm} / \mathrm{min}$ rate registering higher UTS values than that by the $2 \mathrm{~mm} / \mathrm{min}$ rate. The stiffness of the composites in tension thus increases at the 
expense of their strength when the strain rate is increased. The effect of strain rate on the elastic behaviour of the composites is the limited ductility and enhanced stiffness. The semi-empirical model used in this study closely predicted the experimentally measured tensile and flexural strength of the composites. These observations were utilised to simulate the first three modes of free vibration of two composites, namely, the $50 \mathrm{wt} \%$ and $60 \mathrm{wt} \%$ samples, and the plain PP using ANSYS $^{\circledR}$ ver. 12.1 program. The natural frequencies corresponding to the elastic response of the composites at the two strain rates for these modes fluctuate between $208 \mathrm{~Hz}$ and $725 \mathrm{~Hz}$. The results of the simulation are in agreement with the general linear relationship between natural frequency and material stiffness. The strain rate effect, which is not accounted for in the semi-empirical model used for predicting the UTS, and the influence of fibre surface treatment(s) on the elastic behaviour of the kenaf/PP composites, will be studied as part of future work.

\section{Acknowledgement}

The work reported here is funded by the Ministry of Higher Education Malaysia under the auspices of the Fundamental Research Grant (FRGS). This support is gratefully acknowledged.

\section{References}

[1] Huntington, C.G., Permanent architectural fabric structures - Performance of the new materials technology. Construction and Building Materials, 1(2), pp.63-70, 1987.

[2] Chalmers, D.W., Experience in design and production of FRP marine structures. Marine Structures, 4(2), pp.93-115, 1991.

[3] McConnell, V.P., Application of composites in sporting goods. Comprehensive Composite Materials, ed. A. Kelly and C. Zweben, Pergamon: Oxford, pp.787-809, 2000.

[4] Wambua, P., Vangrimde, B., Lomov, S. and Verpoest, I., The response of natural fibre composites to ballistic impact by fragment simulating projectiles. Composite Structures, 77, pp.232-240, 2007.

[5] Mohanty, A.K., Misra, M. and Drzal, L.T., Sustainable bio-composites from renewable resources: Opportunities and challenges in the green materials world. Journal of Polymers and the Environment, 10 (1 and 2), pp.19-26, 2002.

[6] Jering, A. et al., Use of renewable raw materials with special emphasis on chemical industry. ETC/SCP Report 1/2010, European Environment Agency (EEA), UBA and Nova-Institute GmbH, 03/2010, 2010.

[7] John, M.J. and Thomas, S., Biofibres and biocomposites. Carbohydrate Polymers, 71, pp.343-364, 2008.

[8] Ashori, A., Wood-plastic composites as promising green-composites for automotive industries. Bioresource Technology, 99(11), pp.4661-4667, 2008. 
[9] Suddell, B.C., Industrial fibres: Recent and current developments. Proc. of the Symposium on Natural Fibres, Common Fund of Commodities: Rome, pp.71-82, 2009.

[10] Tolinski, M., Applications: Demonstrations of plastics sustainability (Chapter 4). Plastics and Sustainability: Towards a Peaceful Coexistence between Bio-based and Fossil Fuel-based Plastics, ed., John Wiley and Sons: New Jersey, pp.133-167, 2011.

[11] Ross, S. and Evans, D., The environmental effect of reusing and recycling a plastic-based packaging system. Journal of Cleaner Production, 11(5), pp.561-571, 2003.

[12] Peter, K. and Gerd, K., Headspace-SPME-GC-MS identification of volatile organic compounds released from expanded polystyrene. Journal of Polymers and the Environment, 12(2), pp.83-87, 2004.

[13] Mushrooms Made Into Green Packing Material. http://www.naturalnews.com/029463_mushrooms_packing_material.html

[14] Hull, D. and Clyne, T.W., An Introduction to Composite Materials, Cambridge University Press: England, pp.105-132, 1996.

[15] David, N.V., Rozli, Z. and Jailani, M.J.N., Effect of silane coupling agent on the mechanical properties of oil palm frond fibre / polyester composite. Proc. of $2^{\text {nd }}$ International Conference on Advanced and Strategic Technologies - Vol. I, Universiti Kebangsaan Malaysia: Bangi, Malaysia, pp.781-790, 2000.

[16] Li, X., Lope, T.G. and Satyanarayan, P., Chemical treatments of natural fibre for use in natural fibre-reinforced composites: A review. Journal of Polymer and Environment, 12, pp.25-33, 2007.

[17] Bower, D.I., An Introduction to Polymer Physics, Cambridge University Press: England, pp.221-222, 2002.

[18] Fu S.-Y., Feng, X.Q., Lauke Bernd and Mai, Y.M., Effects of particle size, particle/matrix interface adhesion and particle loading on mechanical properties of particulate-polymer composites. Composites: Part B, 3, pp.933-961, 2008. 